\title{
Yuanhuatine from Daphne genkwa selectively induces mitochondrial apoptosis in estrogen receptor $\alpha$-positive breast cancer cells in vitro
}

Authors

Ying-Ying Zhang ${ }^{1}$, Xin-Yue Shang ${ }^{1}$, Xue-Wen Hou ${ }^{1}$, Ling-Zhi Li ${ }^{1}$, Wei Wang ${ }^{1}$, Toshihiko Hayashi ${ }^{2,3}$, Yan Zhang ${ }^{1}$, Guo-Dong Yao ${ }^{1}$, Shao-Jiang Song ${ }^{1}$

\section{Affiliations}

1 School of Traditional Chinese Materia Medica, Key Laboratory of Computational Chemistry-Based Natural Antitumor Drug Research \& Development, Liaoning Province, Shenyang Pharmaceutical University, People's Republic of China;

2 China-Japan Research Institute of Medical and Pharmaceutical Sciences, Wuya College of Innovation, Shenyang Pharmaceutical University, Shenyang, China

3 Department of Chemistry and Life Science, School of Advanced Engineering, Kogakuin University, Tokyo, Japan

Key words

Daphne genkwa, Thymelaeaceae, breast cancer, estrogen receptor $\alpha$, apoptosis

received April 24, 2019

revised August 14, 2019

accepted September 12, 2019

Bibliography

DOI https://doi.org/10.1055/a-1013-1439

Published online October 18, 2019 | Planta Med 2019; 85:

1275-1286 @ Georg Thieme Verlag KG Stuttgart · New York | ISSN 0032-0943

Correspondence

Prof. Shao-jiang Song

School of Traditional Chinese Materia Medica,

Shenyang Pharmaceutical University

Wenhua Road 103, Shenhe District, 110016 Shenyang,

Liaoning Province, People's Republic of China

Phone: + 862443520707 , Fax: + 862443520707

songsj99@163.com

Correspondence

Dr. Guo-Dong Yao

School of Traditional Chinese Materia Medica,

Shenyang Pharmaceutical University

Wenhua Road 103, Shenhe District, 110016 Shenyang,

Liaoning Province, People's Republic of China

Phone: + 862443520793 , Fax: + 862443520793

guodong_yao@126.com
$\Theta$ Supporting information available online at http://www.thieme-connect.de/products

\section{ABSTRACT}

Breast cancer is one of the most common cancers diagnosed among women worldwide. Estrogen receptor alpha $(E R \alpha)$ is a transcriptional factor that plays an important role in the development and progression of breast cancer. Yuanhuatine, a natural daphnane-type diterpenoid extracted from Daphne genkwa, was reported to exhibit significant cytotoxicity against breast cancer cells. However, the underlying mechanism is still unclear. In this study, we evaluated the cytotoxicity of yuanhuatine on two breast cancer cell lines that are ER $\alpha$ positive and -negative. The results show that yuanhuatine inhibits the growth of ER $\alpha$-positive cells (MCF-7) with much stronger inhibitory activity $\left(\mathrm{IC}_{50}=0.62 \mu \mathrm{M}\right)$ compared with positive control tamoxifen $\left(\mathrm{IC}_{50}=14.43 \mu \mathrm{M}\right)$. However, no obvious cytotoxicity was observed in ER $\alpha$-negative cells (MDA-MB-231). Subsequent experiment also indicated that yuanhuatine markedly induced mitochondrial dysfunction, leading to apoptosis in MCF-7 cells. Molecular docking studies suggest the potential interactions between yuanhuatine and ER $\alpha$. Immunofluorescence staining and Western blot analysis indicated that yuanhuatine down-regulated the expression of ER $\alpha$ in MCF-7 cells. MPP, a specific ER $\alpha$ inhibitor, significantly enhanced yuanhuatine-induced mitochondrial dysfunction and apoptosis in MCF-7 cells. On the contrary, the treatment with yuanhuatine causes no apoptosis in MM231 cells. Altogether, in vitro and in silico results suggested that ER $\alpha$ downregulation was involved in yuanhuatine-induced mitochondrial dysfunction and apoptosis in ER $\alpha$-positive breast cancer cells. Thus, yuanhuatine could be a potential candidate for treating $\mathrm{ER} \alpha$-positive breast cancer. 


$\begin{array}{ll}\text { ABBREVIATIONS } \\ \text { ER } \alpha & \text { estrogen receptor alpha } \\ \text { ERK } & \text { extracellular signal-regulated kinase } \\ \text { MEK } & \text { mitogen-activated protein kinase kinase } \\ \text { MM231 } & \text { MDA-MB-231 } \\ \text { MMP } & \text { mitochondrial membrane potential } \\ \text { MTOR } & \text { mammalian target of rapamycin } \\ \text { ROS } & \text { reactive oxygen species }\end{array}$

\section{Introduction}

Breast cancer is currently one of the most prevalent cancers and the leading cause of cancer-related deaths among women worldwide [1]. The pathogenesis of breast cancer has been considered to be associated with hormone stimulation of estrogen receptor alpha $(E R \alpha)$ [2]. It has been known that ER $\alpha$ is overexpressed in approximately $65 \%$ of human breast cancers [3], which is critical for estrogen-dependent growth. Therefore, the diagnosis of breast cancer falls into two broad categories (ER $\alpha$-positive or $E R \alpha$-negative) based on the presence or absence of ER $\alpha$ in cancer cells. Despite advances in diagnosis and target-treatment in ER $\alpha$ positive breast cancer, a poor outcome still remains $[4,5]$. Thus, more effective and selective agents are required for the treatment of ER $\alpha$-positive breast cancer.

Recently, interest in natural compounds as anticancer agents has grown, in the aspects of long term use and safety. As a wellknown traditional A Chinese medicine, Daphne genkwa, from the dried flower buds of Daphne genkwa Sieb. et Zucc. (Thymelaeaceae), has been used for diuretic, antitussive, abortifacient, and antitumor efficacy in the past centuries [6]. Previous phytochemical studies on the chemical components in the flower buds of this plant have identified a series of constituents, including daphnanetype diterpenoids [7]. Daphnane-type diterpenoids are typical biologically active constituents existing predominantly in Daphne genkwa, which exhibited excellent inhibitory activities against a variety of human cancer cells [8-10].

In this study, yuanhuatine ( $\vee$ Fig. 1 A), a daphnane-type diterpenoid, isolated in our lab from an ethanol extract of the flower buds of Daphne genkwa as previously described [11], is shown to exhibit significant growth inhibitory effects. The effect on ER $\alpha$ positive breast cancer cell lines is far stronger than that of tamoxifen, a well-known drug. The primary objective of this study is to examine the growth inhibitory effects of yuanhuatine on human breast cancer cells in vitro and to elucidate the underlying molecular mechanisms.

\section{Results}

Our previous study evaluated the inhibitory effects of yuanhuatine on 10 selected human cancer cell lines [11]. The results showed that yuanhuatine displayed extensive inhibitory effects in most cancer cell lines, especially in MCF-7. Therefore, two breast cancer cell lines (MCF-7 and MM231), as well as human normal epithelial cells (MCF10A) were further investigated by sulforhodamine $B(S R B)$ assay for the inhibitory effects of yuanhuatine
$(0-100 \mu \mathrm{M})$ after $48 \mathrm{~h}$ treatment of the cells. As shown in - Fig. 1 B, yuanhuatine exhibited significant inhibitory effect on MCF-7 cells (ER $\alpha$-positive) with an IC 50 of $0.62 \mu \mathrm{M}$, less inhibitory effect in MM231 (ER $\alpha$-negative) cells, and no obvious toxic effect in normal MCF10A. It's worth mentioning that yuanhuatine exhibited even more potent inhibitory capacity than tamoxifen which was used as a positive control ( $\bullet$ Fig. $1 \mathbf{C}$ ).

These results indicate that yuanhuatine possesses a potent capacity of repressing ER $\alpha$-positive cells (MCF-7) more selectively than ER $\alpha$-negative cells (MM231).

The results in $\mathbf{F i g}$. 1 showing the selectively growth inhibitory effect of yuanhuatine motivated us to further investigate the underlying mechanisms in MCF-7 cells. Apoptotic cells undergo characteristic changes in cell morphology, including rounding, shrinkage and membrane blebbing [12]. Such morphological changes were observed in yuanhuatine-treated MCF-7 cells by phase contrast microscopy ( $\triangleright$ Fig. 2A). Meanwhile, nuclear chromatin condensation and fragmentation were examined by Hoechst 33258 staining in MCF-7 cells after treatment with yuanhuatine ( $\triangleright$ Fig. 2 B). The induction of apoptosis in MCF-7 cells was further analyzed by flow cytometry ( $\vee$ Fig. 2 C). We further determined the protein expression of the key executors of cell apoptosis, PARP and caspase-7 [13]. Western blot analysis showed that treatment of yuanhuatine decreased the levels of pro-caspase-7 and PARP, and increased the level of cleaved caspase-7 ( Fig. 2D, E).

Cell viability increased when cells were co-treated with yuanhuatine and Z-VAD-fmk, a pan caspase inhibitor [14], $(20 \mu \mathrm{M})$, where the percentages of apoptotic cells decreased markedly ( $\vee$ Fig. 2 F, G). These data indicate that yuanhuatine induces apoptosis through a caspase-mediated pathway in MCF-7 cells.

Mitochondria play a central role in regulating apoptosis. It has been reported that the decrease of mitochondrial membrane potential (MMP) and subsequent release of reactive oxygen species (ROS) induce cell death via activating mitochondrial pathway of apoptosis [15,16]. Rhodamine 123 assay and JC-1 assay were used to determine the loss of MMP induced by yuanhuatine treatment in MCF-7 cells ( $\bullet$ Fig. 3 A-D). To examine whether collapse of mitochondrial membrane could induce ROS production, we next investigated the intracellular ROS levels using $\mathrm{H}_{2}$ DCF-DA staining. The results demonstrated that yuanhuatine significantly induced ROS generation ( $\triangleright$ Fig. 3 E, F). Meanwhile, mitochondrial superoxide accumulation was also measured using MitoSOX Red reagent. Treatment with yuanhuatine showed a significant increase of mitochondrial superoxide production as reflected by the increased of red fluorescence in MCF-7 cells ( $\bullet$ Fig. $3 \mathbf{G}, \mathbf{H}$ ).

The $\mathrm{BCl}-2$ protein family, including the anti-apoptotic protein $\mathrm{Bcl}-2$ and pro-apoptotic protein Bax, is crucial for the regulation of mitochondrial apoptosis [17]. Yuanhuatine increased the Bax/ $\mathrm{Bcl}-2$ ratio, which was 3.5 -fold $(0.5 \mu \mathrm{M})$ than untreated cells ( $\vee$ Fig. 3I, J). Taken together, these data demonstrated that yuanhuatine induces mitochondrial dysfunction and mitochondrial apoptosis in MCF-7 cells.

As shown in the above results, ER $\alpha$-positive cells were more sensitive to yuanhuatine treatment compared to ER $\alpha$-negative cells. To investigate whether ER $\alpha$ plays a key role in yuanhuatinetreated breast cancer cells, computational molecular docking 


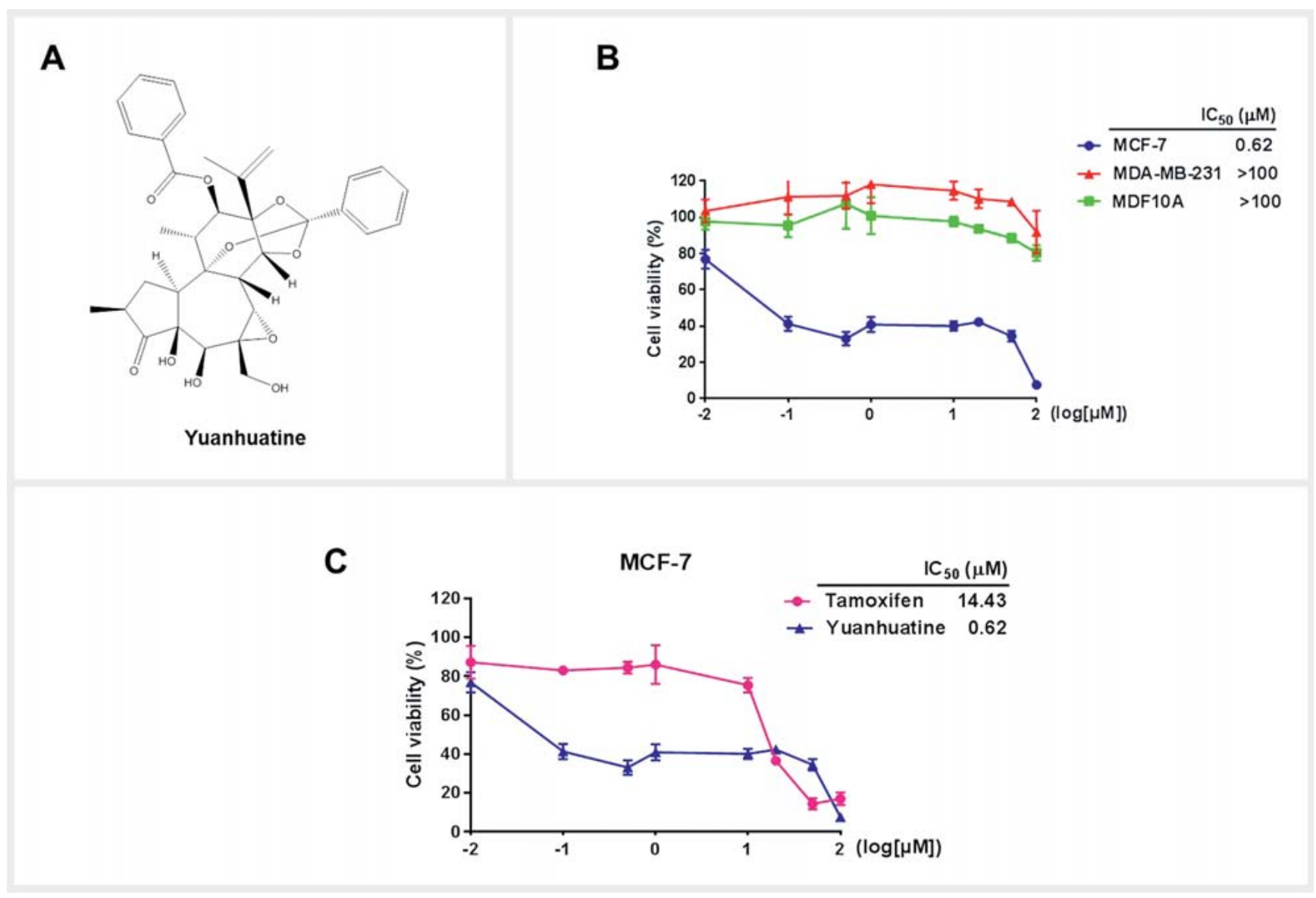

- Fig. 1 Effect of yuanhuatine on cell viability in various cancer cell lines and normal MCF10A. A The chemical structure of yuanhuatine. B MCF-7, MM231 and MCF10A were treated with yuanhuatine at different concentrations $(0-100 \mu \mathrm{M})$ for $48 \mathrm{~h}$, and the $\mathrm{IC}_{50}$ values were quantified using the SRB assay. C MCF-7 cells were treated with yuanhuatine and tamoxifen at different concentrations $(0-100 \mu \mathrm{M})$ for $48 \mathrm{~h}$, and cell viability was determined by SRB assay.

studies were performed to simulate the potential binding mode between yuanhuatine and $\mathrm{ER} \alpha$. Results from in silico studies reveal that yuanhuatine forms key hydrophobic interactions in the hydrophobic pocket with some crucial lipophilic residues (Phe 404, Leu 391, Leu 387, Ala 350, Leu 346, Met 421 and Leu 525) as seen in ligand estradiol binding ( $\mathbf{F i g . 4 A , B}$ ). This pocket could partly overlap with the ATP phosphate-binding region. Based on the above results, we deduce that yuanhuatine could bind to ER $\alpha$.

To evaluate the expression of ER $\alpha$ in yuanhuatine-treated MCF7 cells, we examined the expression of ER $\alpha$ protein using immunofluorescence staining. As shown in - Fig. 5 A, B, compared with the control group, the fluorescence intensity of ER $\alpha$ per area is significantly decreased after yuanhuatine treatment, indicating that treatment with yuanhuatine reduces the level of ER $\alpha$ expression both in the nucleus and the cytosol. Numerous cases have shown that Akt/mTOR and MEK/ERK signaling molecules are important downstream molecules of $\operatorname{ER} \alpha[18,19]$. We next used Western blot to test the protein expression of ER $\alpha$ and downstream molecules, which were regulated by yuanhuatine ( $\vee$ Fig. 5C,D). These data confirmed that yuanhuatine inhibited $\mathrm{ER} \alpha$ signaling pathway in MCF-7 cells.
To further elucidate the effect of ER $\alpha$ on yuanhuatine-induced cell death in MCF-7 cells, MPP, the specific ER $\alpha$-antagonist was applied in the following experiments. The results from $>$ Fig. 6 indicated that cell viability decreased significantly when the cells were co-incubated with yuanhuatine and MPP $(5 \mu \mathrm{M})$. MPP $(5 \mu \mathrm{M})$ alone showed no significant cytotoxicity. Annexin V-FITC/PI analysis and Western blots were performed to confirm yuanhuatine-induced apoptosis via ER $\alpha$ ( $\bullet$ Fig. 7). As shown in $\triangleright$ Fig. 8 compared with yuanhuatine-treated group, co-treatment with MPP resulted in a further reduced MMP and more increased of ROS levels. Yuanhuatine increased the $\mathrm{Bax} / \mathrm{BCl}-2$ ratio, while co-treatment with MPP increased the ratio furthermore ( $\bullet$ Fig. 9 ). The results indicate that ER $\alpha$ down-regulation contributes to mitochondrial dysfunction and hence apoptosis in yuanhuatine-treated MCF-7 cells.

Besides, we examined the expressions of downstream signaling molecules of ER $\alpha$ pathway. The levels of mTOR, p-Akt, p-ERK and ERK were further decreased after co-treatment with yuanhuatine and MPP ( $\triangleright$ Fig. 10). These data confirmed that yuanhuatine inhibited ER $\alpha$ expression and further down-regulated the downstream molecules.

To further confirm the effect of yuanhuatine in ER $\alpha$-positive breast cancer cells, MM231 cells were examined by flow cytome- 
A

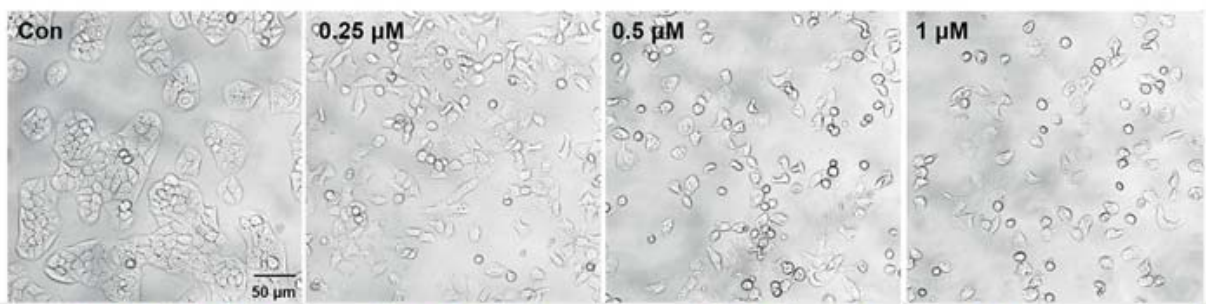

B

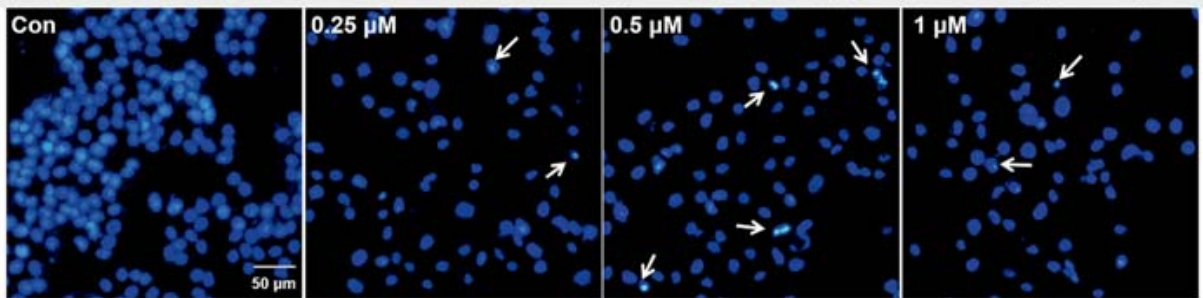

C

Yuanhuatine $(\mu \mathrm{M})$
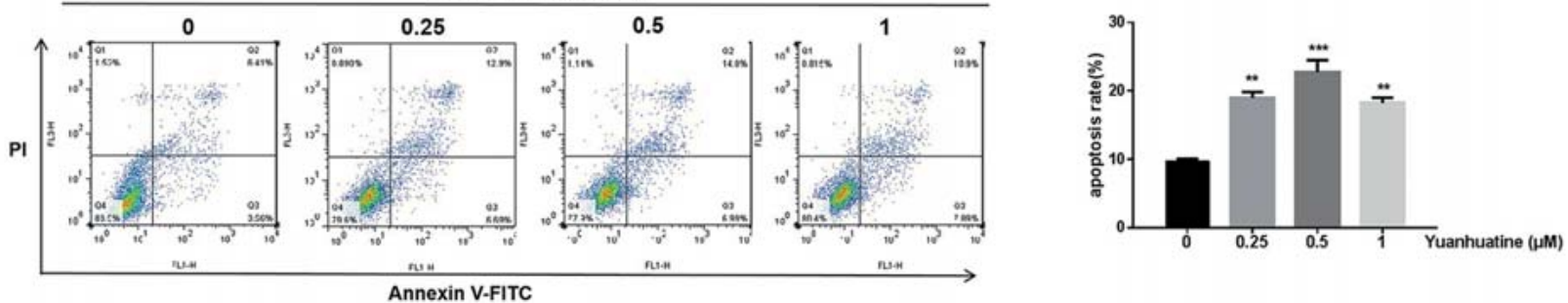

D

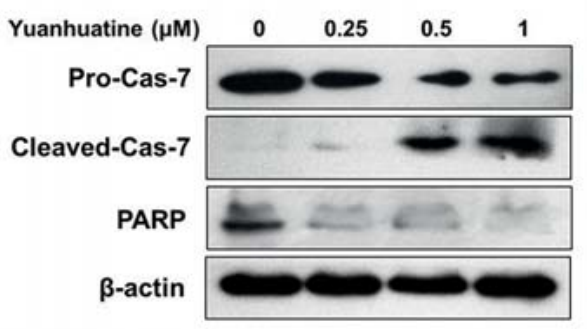

E
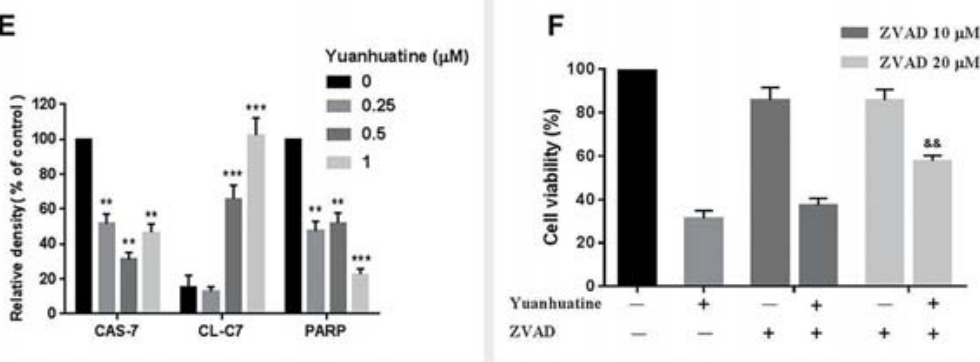

G
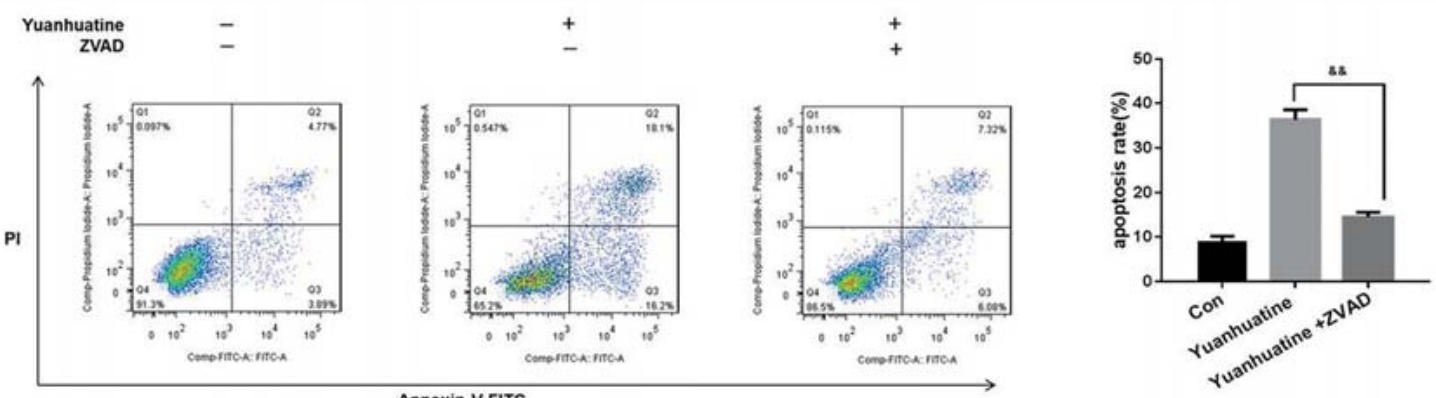

- Fig. 2 Yuanhuatine-induced apoptosis in MCF-7 cells. A Morphological changes of MCF-7 cells during the culture with DMSO or $0.25,0.5,1 \mu M$ of yuanhuatine for $48 \mathrm{~h}$ were observed with a phase contrast microscope $(200 \times)$. Cell shrinkage and rounding of the cell shape were observed. Representative images of MCF-7 cells with $50 \mu \mathrm{m}$ scale bars are shown. B MCF-7 cells were treated with DMSO or $0.25,0.5,1 \mu \mathrm{M}$ of yuanhuatine for $48 \mathrm{~h}$ and stained with Hoechst 33258 . The morphological changes of nuclei were examined by fluorescence microscopy (200x). Representative images of MCF-7 cells are shown with white arrows indicating apoptotic cells. Scale bar; $50 \mu \mathrm{m} \mathrm{C} \mathrm{MCF-7} \mathrm{cells} \mathrm{were} \mathrm{treated} \mathrm{with} \mathrm{yuanhuatine} \mathrm{for}$ $48 \mathrm{~h}$, stained with Annexin V-FITC in a buffer containing PI, and analyzed by flow cytometry. D, E The expressions of pro-caspase-7, cleaved caspase-7 and PARP were analysed by western blotting. F MCF-7 cells were pretreated with or without Z-VAD-fmk for $1 \mathrm{~h}$, followed by the treatment with $0.5 \mu \mathrm{M}$ yuanhuatine for another $48 \mathrm{~h}$. Cell viability was determined by SRB assay. G Apoptosis was analyzed by flow cytometry. The results are expressed as means \pm SD for each group. ${ }^{* *} p<0.01 ;{ }^{* *} p<0.001$ versus control. ${ }^{\& \&} p<0.01$; compared with yuanhuatine alone. 


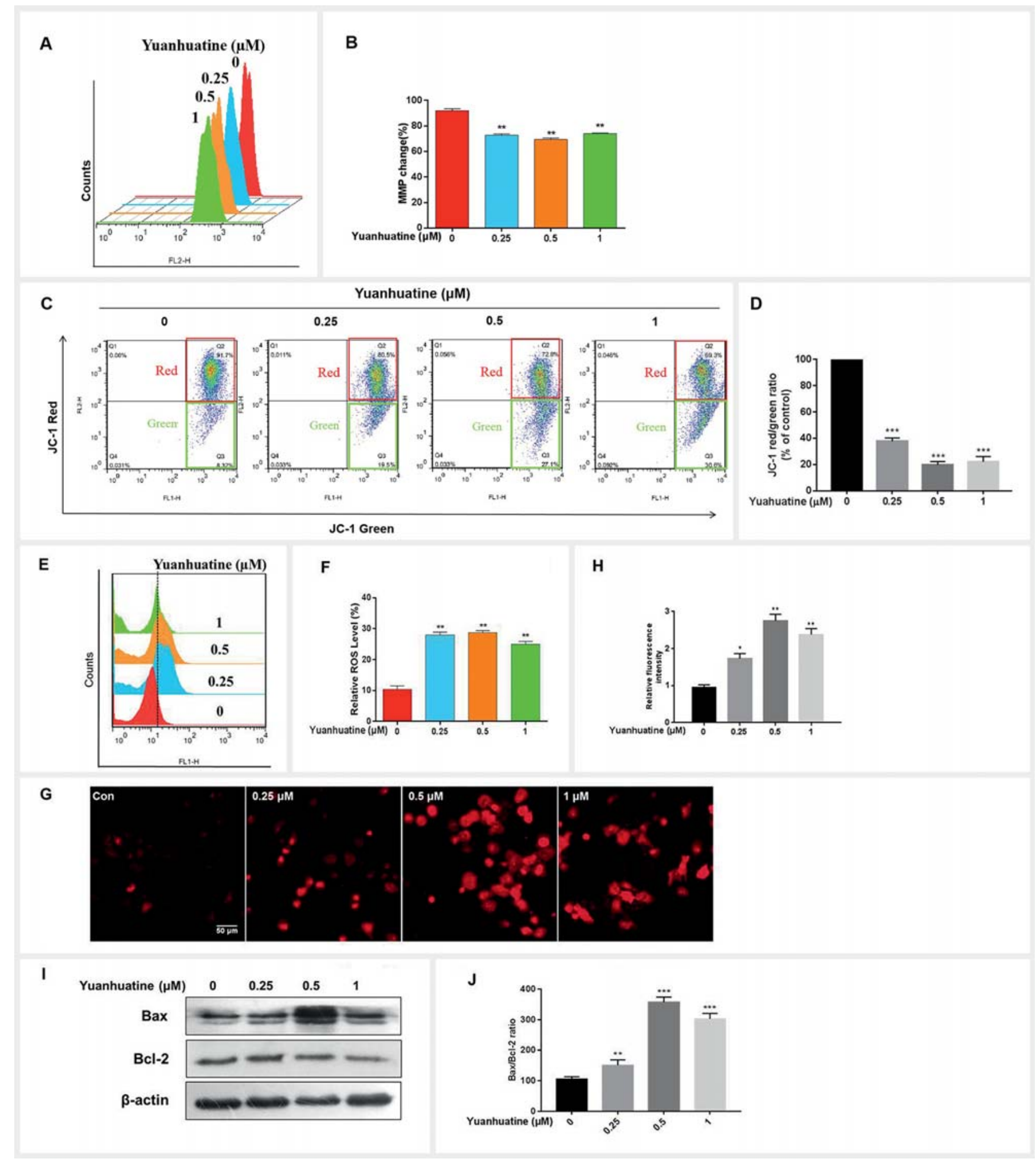

- Fig. 3 Yuanhuatine-triggered apoptosis is associated with mitochondrial dysfunction. A, B The MMP of MCF-7 cells treated with yuanhuatine $(0,0.25,0.5,1 \mu \mathrm{M})$ for $48 \mathrm{~h}$, was obtained by staining with Rhodamine 123 followed by flow cytometric analysis. C, D The MMPs of MCF-7 cells were determined by JC-1 staining, followed by flow cytometric analysis. E, F ROS levels were determined by flow cytometry after staining with $\mathrm{H}_{2}$ DCF-DA. G, H Mitochondrial superoxide production was evaluated by MitoSOX staining with a fluorescence microscope $(200 \times)$. I,J The levels of Bax and Bcl-2 were determined by western blotting. The results are expressed as means \pm SD for each group. ${ }^{* *} p<0.01 ;{ }^{* * *} p<0.001$ versus control. 
A
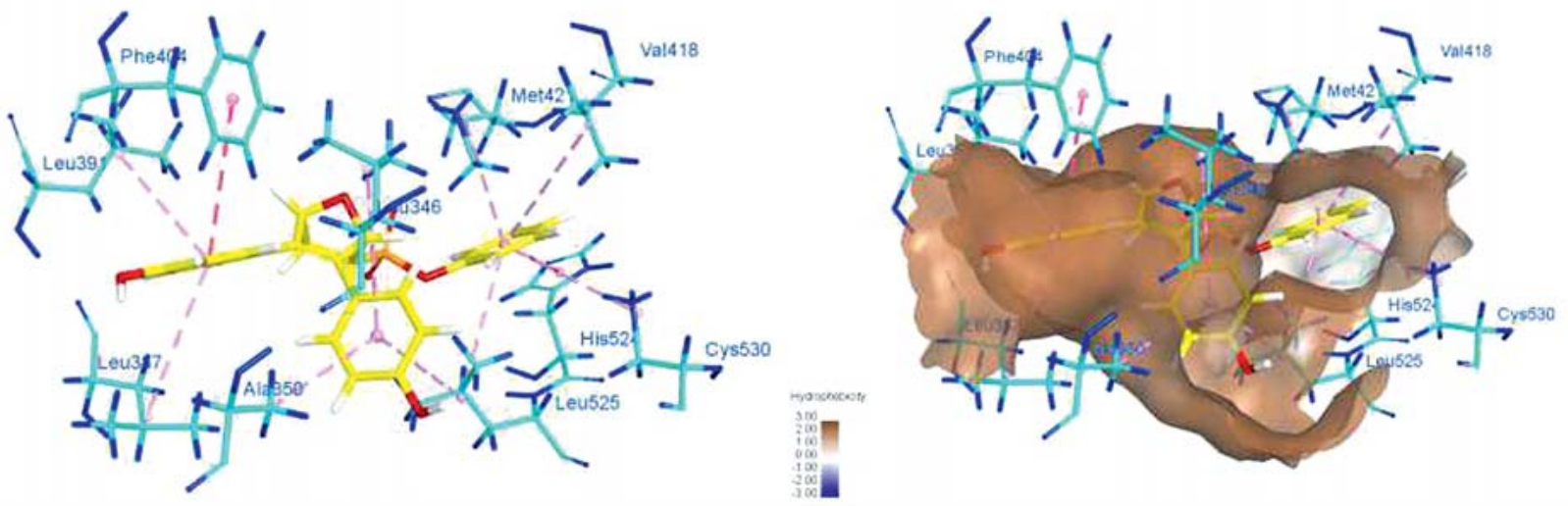

B
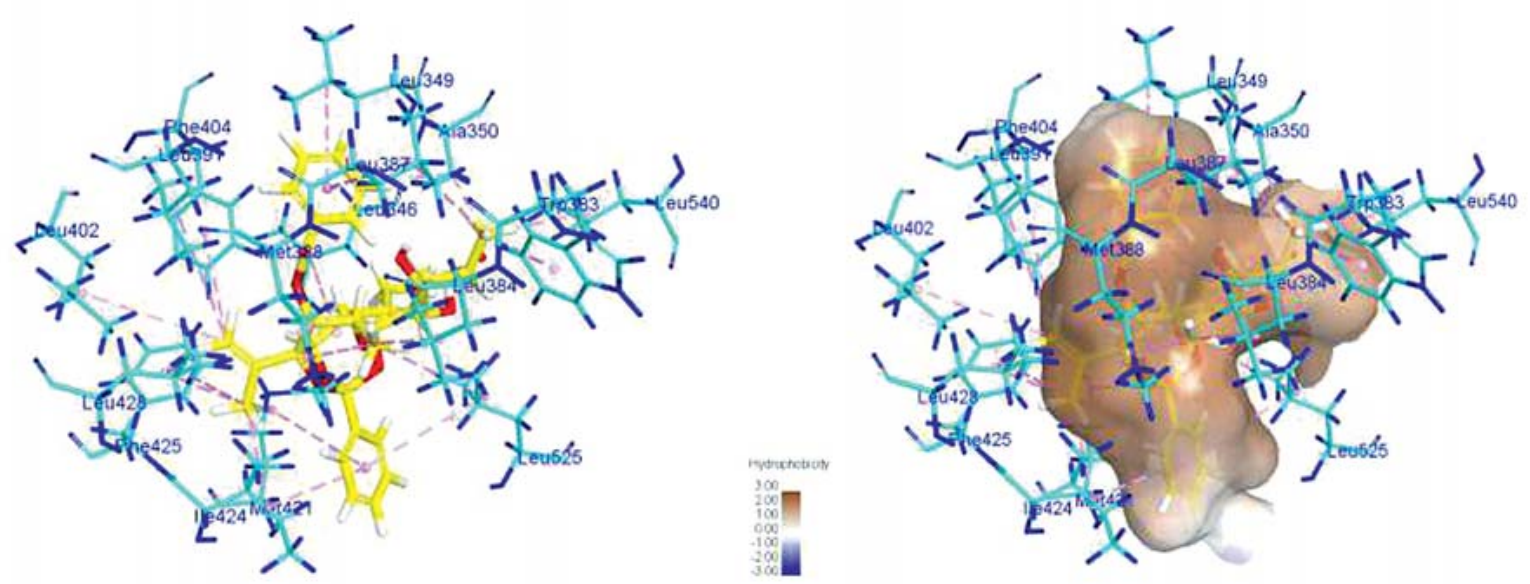

- Fig. 4 Molecular docking studies. A The binding mode of ligand in the active site of ER $\alpha$ pocket. Hydrophobic surface of ligand towards ER $\alpha$ pocket. B The binding mode of yuanhuatine in the active site of ER $\alpha$ pocket. Hydrophobic surface of yuanhuatine towards ER $\alpha$ pocket. Yuanhuatine (yellow carbon) in contact with amino acids residues (cyan carbon) were presented in sticks. Hydrophobic interactions were highlighted in carnation dashed lines. Hydrophobic surface in receptor residues were indicated from blue (hydrophilic) to brown (hydrophobic).

try analysis. As expected, MM231 cells were resistant to yuanhuatine (Fig. 1S, Supporting Information), which may indicate that necessity of the change from upregulation to downregulation of $E R \alpha$ in yuanhuatine-induced apoptosis.

\section{Discussion}

$\mathrm{ER} \alpha$ is a member of the steroid receptor superfamily that regulates processes such as growth and differentiation in various target cells [20]. Currently, the most popular classification of breast cancer is according to the ER $\alpha$ status in selecting appropriate chemotherapeutic drugs [21]. Clinically, selectively inhibition of ER $\alpha$ has long been considered a critical and effective strategy to prevent the development and progression in breast cancer [22]. Up to date, various natural materials have been reported to inhibit breast cancer cells growth by down-regulating ER $\alpha$ expression [23-26]. Therefore, it is of great importance to develop novel chemicals, which are more selective to $E R \alpha$, but have fewer side effects for the treatment of breast cancer.
Natural products were potential sources of chemotherapy for breast cancer [27]. Daphnane-type diterpenoids are known to be the main types of plant diterpenoid orthoesters with significant biological activity [28]. Yuanhuatine, a natural daphnane-type diterpenoid deriving from Daphne genkwa, exhibits significant inhibitory effect in 10 selected human cancer cell lines in our previous study [11]. However, detailed mechanism of anti-tumor effect of yuanhuatine in breast cancer cells has not been reported. In this study, our results demonstrate that yuanhuatine induces mitochondrial apoptosis by repression of ER $\alpha$ level.

Due to the potent anti-tumor effects of yuanhuatine, we further predicted the pharmacokinetic properties and drug-likeness properties of yuanhuatine using PreADMET web server (http:// preadmet.bmdrc.kr). From Table 1S (Supporting Information), we identified that yuanhuatine exhibited good predicted pharmacokinetic properties. In addition, Ames test suggested yuanhuatine showed non-toxicity. These results suggest that yuanhuatine has a therapeutic potential for the treatment of breast cancer. 


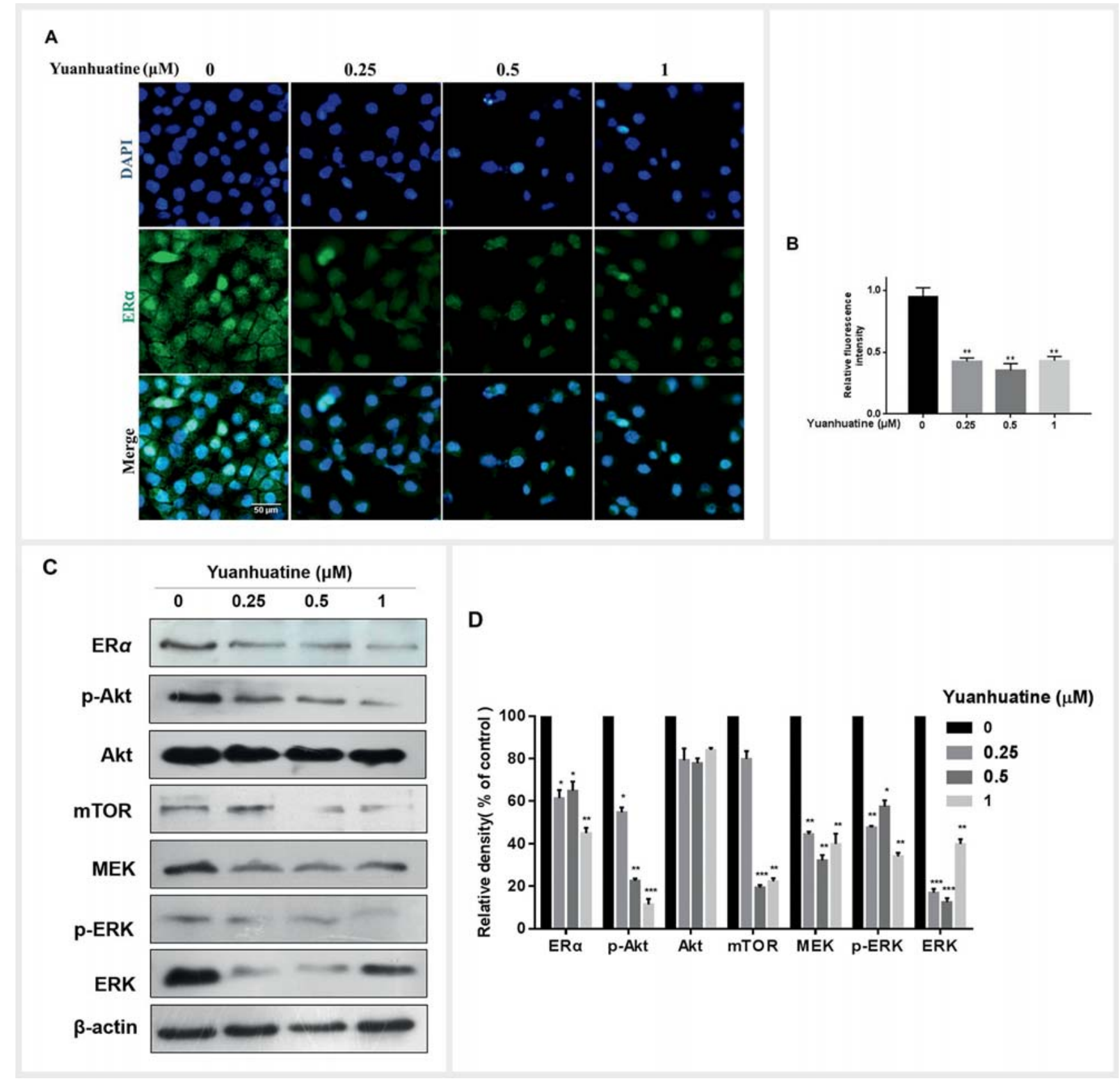

- Fig. 5 Yuanhuatine decreased ER $\alpha$ and down-regulated Akt/mTOR and MEK/ERK signaling pathways in MCF-7 cells. A, B The expression of ER $\alpha$ was examined using immunofluorescence staining. Nuclei were labeled with DAPI. The fluorescence intensity per area was counted. C, D The expression levels of ER $\alpha$, p-Akt, Akt, mTOR, MEK, p-ERK and ERK were determined by western blotting. The results are expressed as means \pm SD for each group. ${ }^{*} \mathrm{p}<0.05^{* *} \mathrm{p}<0.01 ;{ }^{* * *} \mathrm{p}<0.001$ versus control.

In summary, our studies have elucidated the notable anti-tumor effect of yuanhuatine via down-regulation of ER $\alpha$ followed by mitochondrial dysfunction and mitochondrial apoptosis in ER $\alpha$-positive breast cancer cell lines. Therefore, yuanhuatine may provide a promising candidate for the treatment of ER $\alpha$-positive breast cancer.

\section{Materials and Methods}

\section{Plant material}

The flower buds of $D$. genkwa were collected from Mianyang, Sichuan province, PR China, in June 2010, and were identified by Professor J.C. Lu (Department of Natural Products Chemistry, Shenyang Pharmaceutical University, PR China). A voucher specimen (No. 20100701) has been deposited in the Herbarium of Shenyang Pharmaceutical University, Liaoning, PR China. 


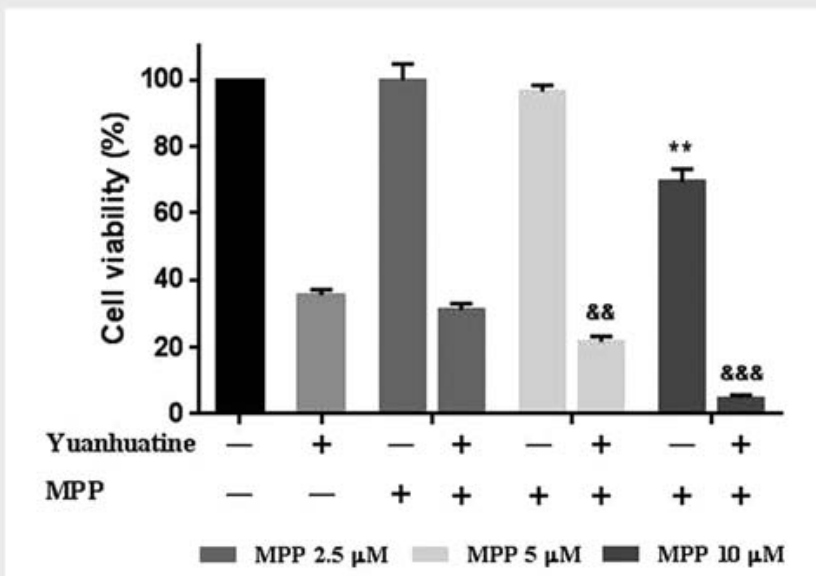

> Fig. 6 MPP (an ER $\alpha$-antagonist) was applied with yuanhuatine to examine the cell viability of MCF-7 cells. The cells were pre-treated with MPP $1 \mathrm{~h}$ prior to the administration of yuanhuatine $(0.5 \mu \mathrm{M})$ that lasted for $48 \mathrm{~h}$, and the cell viability was measured by SRB assay. ${ }^{* *} p<0.01$ versus control; ${ }^{\& \&} p<0.01 ;{ }^{\& \&} p<0.001$ compared with yuanhuatine alone.

\section{Chemicals and reagents}

Yuanhuatine was dissolved in dimethylsulfoxide (DMSO) at a stock concentration of $50 \mathrm{mM}$. Sulforhodamine B (SRB), rhodamine 123, DAPI and ER $\alpha$-specific antagonist MPP 1,3-Bis(4-hydroxyphenyl)-4-methyl-5-[4-(2- piperidinylethoxy)phenol]-1H-pyrazole-dihydro-chloride were purchased from Sigma-Chemical. Fetal bovine serum (FBS) was purchased from CLARK Bioscience. Dulbecco's modified Eagle's medium (DMEM), Phosphate buffered solution (PBS) and Antibiotics $(100 \mathrm{U} / \mathrm{mL}$ penicillin, $100 \mu \mathrm{g} / \mathrm{mL}$ streptomycin) were purchased from HyClone, Inc. caspase-7, Bax, Bcl-2, ER $\alpha, \mathrm{p}$-Akt, Akt, mTOR, MEK, p-ERK, ERK, $\beta$-actin and horseradish-peroxidase-conjugated secondary antibodies (goat anti-rabbit or goat anti-mouse) were purchased from Santa Cruz Biotechnology. Dichlorofluorescein diacetate ( $\mathrm{H}_{2}$ DCF-DA), Hoechst 33258, JC-1, RIPA lysis buffer, BCA assay kit were purchased from Beyotime. Annexin V-FITC was purchased from Bimake. MitoSOX Red mitochondrial superoxide indicator was purchased from Invitrogen. PVDF membranes $(0.2 \mu \mathrm{m})$ were purchased from Millipore.

\section{Cell culture}

MCF-7, MM231 and MCF10A cells were obtained from American Type Culture Collection. Cells were cultured in DMEM medium supplemented with $10 \%$ fetal bovine serum FBS, 100 units $/ \mathrm{mL}$ penicillin, and $100 \mu \mathrm{g} / \mathrm{mL}$ streptomycin. Cells were incubated at

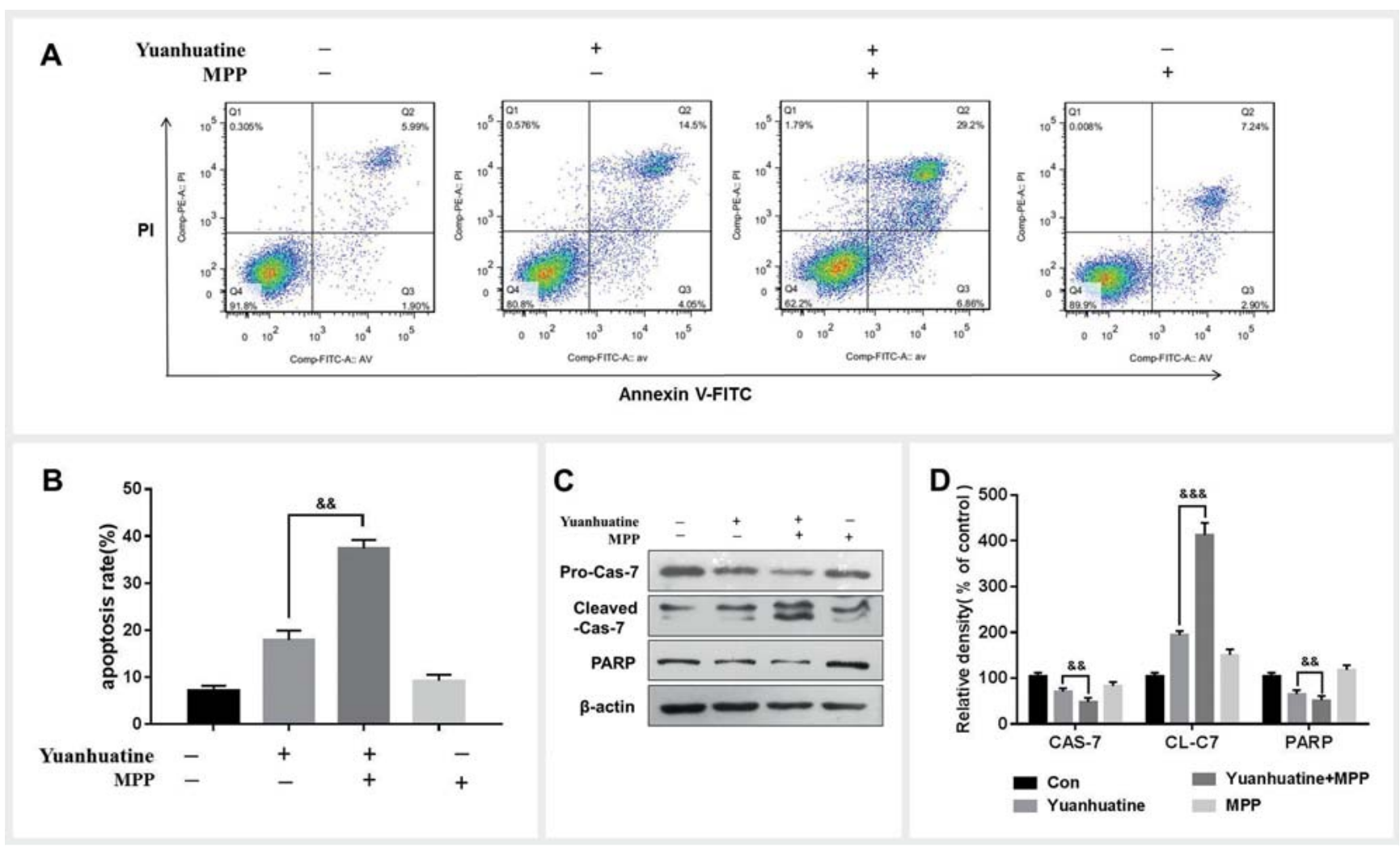

Fig. 7 In the presence of MPP, yuanhuatine-induced apoptosis was examined in MCF-7 cells. A, B The cells were incubated with or without $5 \mu$ M MPP for $1 \mathrm{~h}$; then yuanhuatine was added to a concentration of $0.5 \mu \mathrm{M}$. The cells cultured for another $48 \mathrm{~h}$ were subjected to flow cytometric analysis of apoptotic cell ratios after Annexin V-FITC/PI staining. C, D The expression levels of pro-caspase-7, cleaved caspase-7 and PARP were determined by Western blotting. ${ }^{\& \&} \mathrm{p}<0.01 ; \& \& \mathrm{p}<0.001$ compared with yuanhuatine alone. 


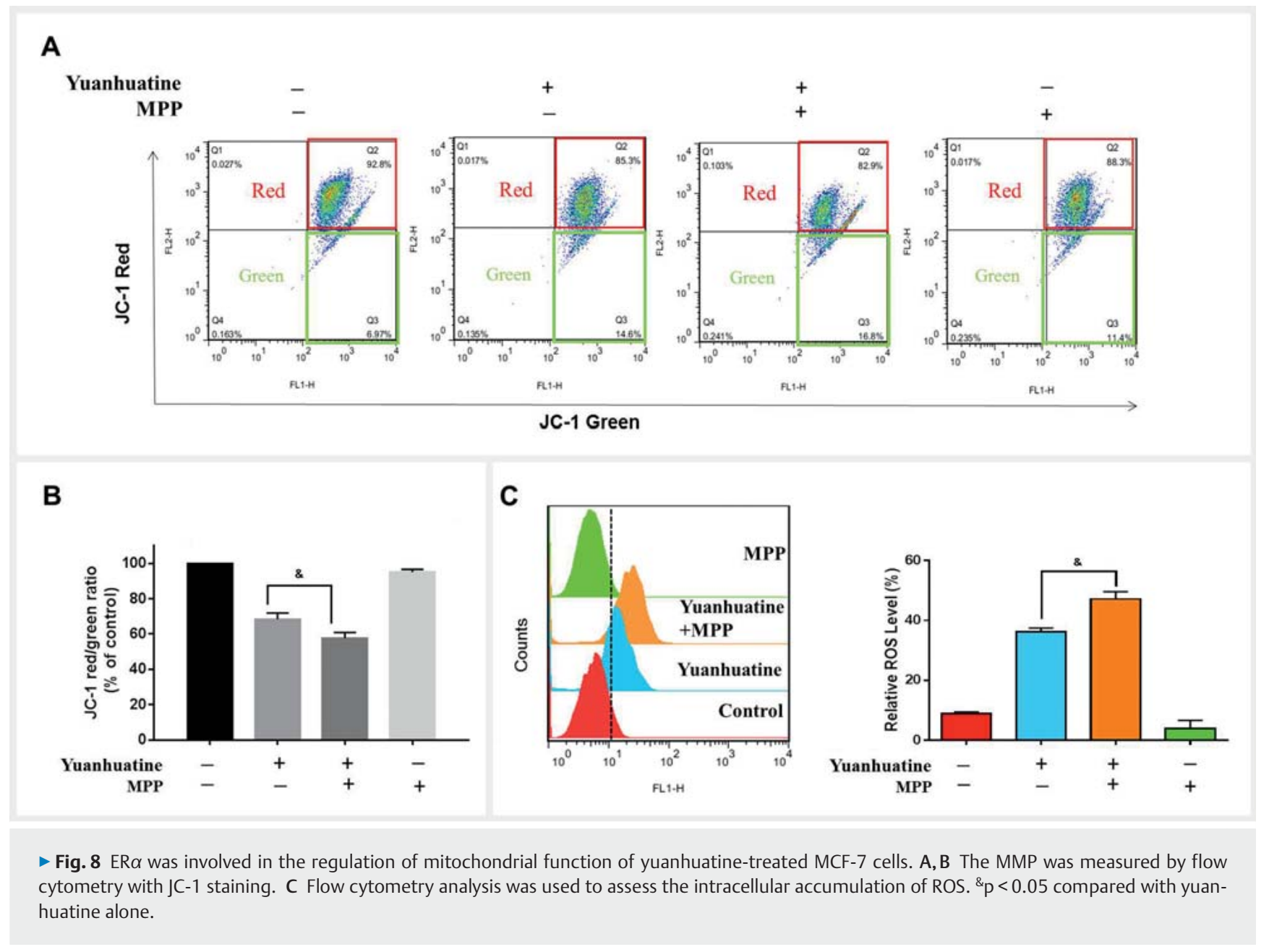

$37^{\circ} \mathrm{C}$ with $5 \% \mathrm{CO}_{2}$ in a humidified atmosphere. All experiments were performed on logarithmically growing cells.

\section{SRB assay}

Sulforhodamine B (SRB) assay was employed for measurement of in vitro growth inhibition and cytotoxicity. Breast cancer cells were seeded at a cell density of $5 \times 10^{3}$ cells/well in 96 -well plates and incubated for $24 \mathrm{~h}$ to allow exponential growth, then treated with yuanhuatine. After $48 \mathrm{~h}$ of treatment, $50 \%$ trichloroacetic acid (TCA) was added to the culture medium, for $1 \mathrm{~h}$ at $4{ }^{\circ} \mathrm{C}$ in the dark, to fix the cells. The plates were then washed with tap water to remove TCA, air-dried and stained for 30 min with $0.4 \%$ (w/v) SRB dissolved in $1 \%$ acetic acid. After incubation, the cultures were rinsed with $1 \%$ acetic acid to remove residual dye, the plates were air-dried and the bound dye was solubilized with $200 \mu \mathrm{L}$ of $10 \mathrm{mM}$ Tris buffer ( $\mathrm{pH}$ 10.5). The absorbance of each well was determined at $540 \mathrm{~nm}$ using a microplate reader. Cell growth inhibitory ratio was calculated using the following equation:

Cell viability ratio $(\%)=100 \% \times\left(A_{540, \text { sample }}-A_{540, \text { control }}\right) /$

$\left(A_{540, \text { control }}-A_{540, \text { blank }}\right)$.

\section{Observation of morphological changes}

Cells were seeded into 12 -well plates $\left(1 \times 10^{5}\right.$ cells/well) and incubated for $24 \mathrm{~h}$ to allow exponential growth, then incubated in the presence or absence of yuanhuatine at the indicated concentrations for $48 \mathrm{~h}$. The cellular morphology was observed by using a phase contrast microscope. Apoptotic nuclear morphology was assessed by fluorescent DNA-binding dye, Hoechst 33258. After incubation, the culture medium was removed. The cells were fixed for $15 \mathrm{~min}$ in $4 \%$ paraformaldehyde, and then incubated in Hoechst $33258(5 \mu \mathrm{g} / \mathrm{mL})$ at room temperature for $30 \mathrm{~min}$. Finally, a fluorescence microscope was used to examine the chromatin condensation.

\section{Cell apoptosis ratio detection}

Cells were seeded into 6-well plates $\left(2 \times 10^{5}\right.$ cells/well) and incubated for $24 \mathrm{~h}$ to allow exponential growth, treated with yuanhuatine for $48 \mathrm{~h}$. After incubation, the cells were washed twice in PBS and resuspended in an Annexin V-FITC/PI staining solution according to the manufacturer's instruction. Apoptotic cells were immediately analyzed by flow cytometry. The samples are then analyzed with Flow jo 7.6.5. 

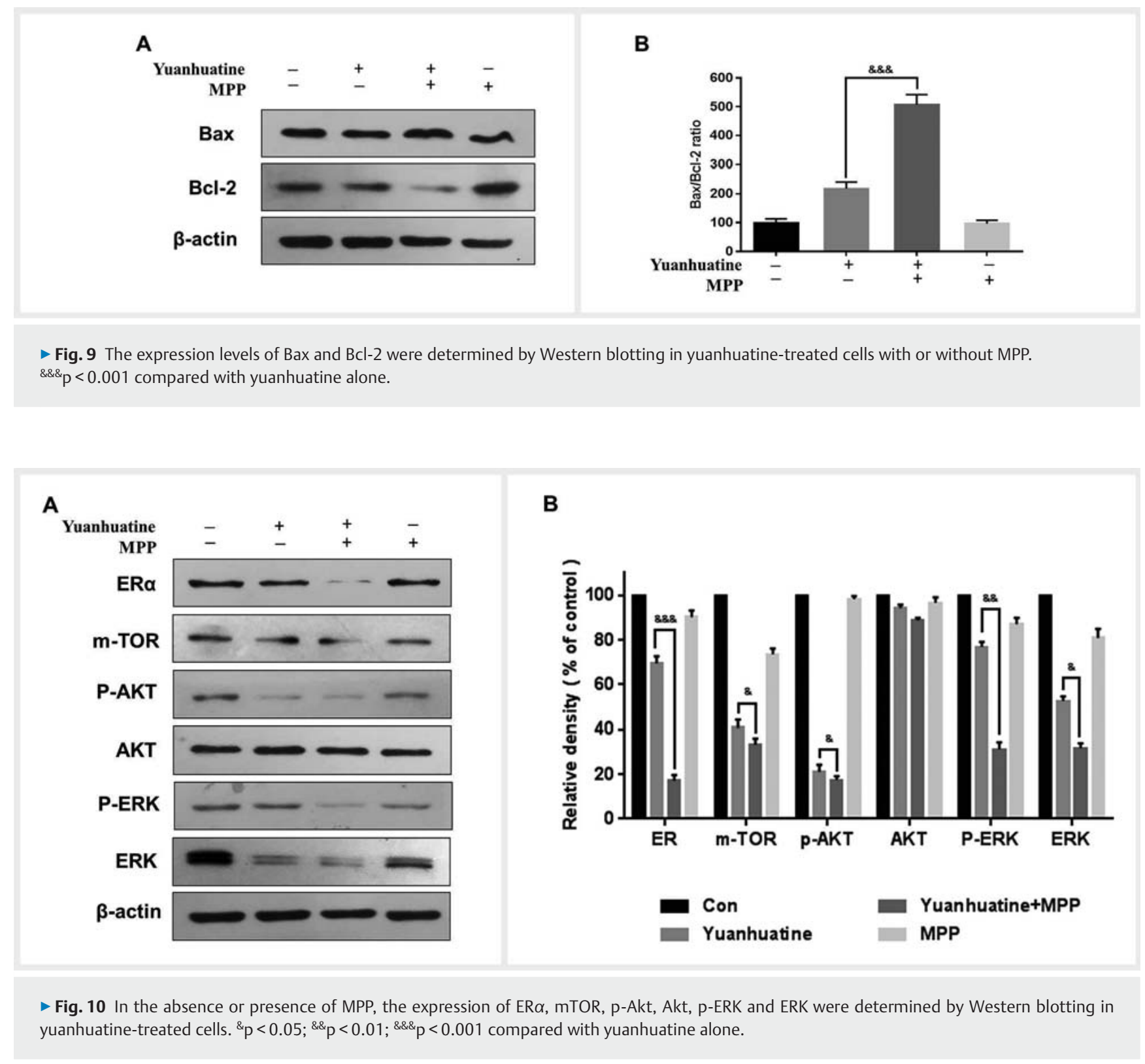

\section{Western blot analysis}

The total cellular samples were harvested and lysed in RIPA buffer [250 mM Tris-HCl (pH 6.8), 4\% SDS, 10\% glycerol, 0.006\% bromophenol blue, $2 \% \beta$-mercaptoethanol, $50 \mathrm{mM}$ sodium fluoride, and $5 \mathrm{mM}$ sodium orthovanadate] and boiled for $10 \mathrm{~min}$ at $100^{\circ} \mathrm{C}$. Equal amount of protein $(35 \mu \mathrm{g})$ were separated on a $10 \%$ SDSPAGE gel and transferred to nitrocellulose membranes. The membranes were blocked with $5 \%$ BSA and probed with a primary antibody $(1: 1000)$ followed by the corresponding secondary antibody $(1: 5000)$. Immunoreactive bands were visualized with a chemiluminescence kit followed by incubation with HRP-conjugated secondary antibodies. The density of protein bands were calculated by the ImageJ software.

\section{Mitochondrial membrane potential (MMP) analysis}

MMP was measured by flow cytometry analysis using Rhodamine 123. Cells $\left(2 \times 10^{5}\right.$ cells/well) were plated in 6 -well plates and incubated for $24 \mathrm{~h}$ to allow exponential growth. The cells were treated with the yuanhuatine for $48 \mathrm{~h}$. The treated cells were collected and analyzed immediately for Rhodamine 123 fluorescence intensity by flow cytometer.

JC-1 assay kit was used to evaluate MMP as well. Breast cancer cells collected were supplemented with $500 \mu \mathrm{L}$ of JC- 1 dye staining solution, and then incubated in the dark at $37^{\circ} \mathrm{C}$ for $20 \mathrm{~min}$. After incubation, the cells were centrifuged at $600 \mathrm{~g}$ for $5 \mathrm{~min}$ and washed twice with incubation buffer. The fluorescence levels were then determined by flow cytometry after the cells were resuspended in $500 \mu \mathrm{L}$ of the incubation buffer. The samples are then analyzed with Flow jo 7.6.5. 


\section{Measurement of intracellular ROS levels}

The intracellular reactive oxygen species (ROS) levels were evaluated using the ROS-specific fluorescent dye $\mathrm{H}_{2}$ DCF-DA $(10 \mu \mathrm{mol} / \mathrm{L})$. After indicated treatments, cells were washed with PBS for three times and stained with $\mathrm{H}_{2}$ DCF-DA, incubated at $37^{\circ} \mathrm{C}$ for $30 \mathrm{~min}$ in the dark. Furthermore, cells were harvested and the levels of ROS were quantified by measuring the intracellular florescent intensities by flow cytometry. Data were then analyzed with Flow Jo.7.6.1.

\section{Mitochondrial superoxide}

To analyze mitochondrial superoxide levels, cells were incubated with MitoSOX $(5 \mu \mathrm{M})$ for 10 minutes at $37^{\circ} \mathrm{C}$. PBS was used to wash the cells and superoxide levels were determined using a fluorescence microscope at 530/590 nm.

\section{Immunofluorescence staining}

MCF-7 cells were washed with PBS, fixed in $4 \%$ paraformaldehyde for 20 min at room temperature, and permeabilized in $0.1 \%$ Triton $X-100$ for $10 \mathrm{~min}$. After blocking with $5 \%$ bovine serum albumin (BSA) for $20 \mathrm{~min}$, the samples were incubated with anti-ER $\alpha$ antibody $(1: 500)$ overnight at $4{ }^{\circ} \mathrm{C}$, followed by reaction with a FITClabelled secondary antibody $(1: 1000)$ at room temperature for $1 \mathrm{~h}$. After being washed with PBS, the cells were incubated with 4, 6-diamidino-2-phenylindole dihydrochloride (DAPI) to stain the nucleus and observed under a fluorescence microscope.

\section{Molecular docking}

The X-ray crystal structure of the ER $\alpha$ (PDB: 5 U2D) and a resolution of $1.86 \AA$ A was obtained from the RCSB protein data bank (PDB) (http://www.wwpdb.org). The protein was optimized by the Sybyl-X (version 2.0, TRIPOS Inc.) software to add all hydrogen atoms and remove water molecules. The structural relation was carried out for the docking calculations using the AUTODOCK 4.2 SUITE of program. The visualization of resulting complex geometry was performed on Discovery Studio 4.5 program.

\section{Statistical analysis}

All results were calculated as means \pm SD for at least three independent experiments. Experimental data were analyzed by oneway or two-way ANOVAs using GraphPad Prism version 6.0. Statistical significance was considered at $P<0.05$

\section{Supporting Information}

Additional information about the induction of cells apoptosis by yuanhuatine treatment of MM231 cells and the pharmacokinetic properties of yuanhuatine predicted by PreADMET web server are available in Supporting Information section.

\section{Acknowledgements}

This research work was supported by National Nature Science Foundation of China (81573319, 81673324, 81872766, 81973528), China Postdoctoral Science Foundation (2017M620104). The Science Research Project of Liaoning of P. R. China (201602705, L2015518).

\section{Conflict of Interest}

The authors declare that they have no conflict of interest.

\section{References}

[1] Siegel RL, Miller KD, Jemal A. Cancer statistics, 2019. CA Cancer J Clin 2019; 69: 7-34

[2] Clemons M, Goss P. Estrogen and the risk of breast cancer. N Engl J Med 2001; 344: 276-285

[3] Ali S, Coombes RC. Estrogen receptor alpha in human breast cancer: occurrence and significance. J Mammary Gland Biol Neoplasia 2000; 5: 271-281

[4] Tong CWS, Wu M, Cho WCS, To KKW. Recent advances in the treatment of breast cancer. Front Oncol 2018; 8: 227

[5] Ballinger TJ, Meier JB, Jansen VM. Current landscape of targeted therapies for hormone-receptor positive, HER2 negative metastatic breast cancer. Front Oncol 2018; 8: 308

[6] Li S, Chou G, Hseu Y, Yang H, Kwan H, Yu Z. Isolation of anticancer constituents from flos genkwa (Daphne genkwa Sieb.et Zucc.) through bioassay-guided procedures. Chem Cent J 2013; 7: 159

[7] Van Minh N, Han BS, Choi HY, Byun J, Park JS, Kim WG. Genkwalathins A and B, new lathyrane-type diterpenes from Daphne genkwa. Nat Prod Res 2018; 32: 1782-1790

[8] Hong JY, Nam JW, Seo EK, Lee SK. Daphnane diterpene esters with antiproliferative activities against human lung cancer cells from Daphne genkwa. Chem Pharm Bull (Tokyo) 2010; 58: 234-237

[9] Park BY, Min BS, Ahn KS, Kwon OK, Joung H, Bae KH, Lee HK, Oh SR. Daphnane diterpene esters isolated from flower buds of Daphne genkwa induce apoptosis in human myelocytic HL-60 cells and suppress tumor growth in Lewis lung carcinoma (LLC)-inoculated mouse model. J Ethnopharmacol 2007; 111: 496-503

[10] Shao ZY, Shang Q, Zhao NX, Zhang SJ, Xia GP, Bai XX, Dong HL, Han YM Daphnane diterpene esters from flower buds of Daphne genkwa and their cytotoxic effects on cancer cells. Zhong Cao Yao 2013; 44: 128132

[11] Li F, Sun Q, Hong L, Li L, Wu Y, Xia M, Ikejima T, Peng Y, Song S. Daphnane-type diterpenes with inhibitory activities against human cancer cell lines from Daphne genkwa. Bioorg Med Chem Lett 2013; 23: 2500-2504

[12] Zhang Y, Chen X, Gueydan C, Han J. Plasma membrane changes during programmed cell deaths. Cell Res 2018; 28: 9-21

[13] Boatright KM, Salvesen GS. Mechanisms of caspase activation. Curr Opin Cell Biol 2003; 15: 725-731

[14] Pero ME, Zullo G, Esposito L, lannuzzi A, Lombardi P, De Canditiis C, Neglia G, Gasparrini B. Inhibition of apoptosis by caspase inhibitor Z-VAD-FMK improves cryotolerance of in vitro derived bovine embryos. Theriogenology 2018; 108: 127-135

[15] Fan S, Li L, Chen S, Yu Y, Qi M, Tashiro S, Onodera S, Ikejima T. Silibinin induced-autophagic and apoptotic death is associated with an increase in reactive oxygen and nitrogen species in HeLa cells. Free Radic Res 2011; 45: 1307-1324

[16] Dharmaraja AT. Role of reactive oxygen species (ROS) in therapeutics and drug resistance in cancer and bacteria. J Med Chem 2017; 60: $3221-3240$

[17] Youle RJ, Strasser A. The BCL-2 protein family: opposing activities that mediate cell death. Nat Rev Mol Cell Biol 2008; 9: 47-59

[18] Saini KS, Loi S, de Azambuja E, Metzger-Filho O, Saini ML, Ignatiadis M, Dancey JE, Piccart-Gebhart MJ. Targeting the PI3K/AKT/mTOR and Raf/ MEK/ERK pathways in the treatment of breast cancer. Cancer Treat Rev 2013; 39: 935-946 
[19] Zheng N, Zhang P, Huang H, Liu W, Hayashi T, Zang L, Zhang Y, Liu L, Xia M, Tashiro S, Onodera S, Ikejima T. ER $\alpha$ down-regulation plays a key role in silibinin-induced autophagy and apoptosis in human breast cancer MCF-7 cells. J Pharmacol Sci 2015; 128: 97-107

[20] Klinge CM. Estrogen receptor interaction with estrogen response elements. Nucleic Acids Res 2001; 29: 2905-2919

[21] Thomas C, Gustafsson JÅ. The different roles of ER subtypes in cancer biology and therapy. Nat Rev Cancer 2011; 11: 597-608

[22] Sommer S, Fuqua SA. Estrogen receptor and breast cancer. Semin Cancer Biol 2001; 11: 339-352

[23] Jang SY, Jang SW, Ko J. Celastrol inhibits the growth of estrogen positive human breast cancer cells through modulation of estrogen receptor $\alpha$. Cancer Lett 2011; 300: 57-65
[24] Kim KH, Cho S], Kim BO, Pyo S. Differential pro-apoptotic effect of allicin in oestrogen receptor-positive or -negative human breast cancer cells. J Funct Foods 2016; 25: 341-353

[25] Lim MS, Choung SY, Jeong KW. Germacrone Inhibits Estrogen Receptor $\alpha$-Mediated Transcription in MCF-7 Breast Cancer Cells. Phytother Res 2016; 30: 2036-2043

[26] Sun Y, Wang Y, Fan C, Gao P, Wang X, Wei G, Wei J. Estrogen promotes stemness and invasiveness of ER-positive breast cancer cells through Gli1 activation. Mol Cancer 2014; 13: 137

[27] Min JB, Gupta SD, Wahler J, Suh N. Role of dietary bioactive natural products in estrogen receptor-positive breast cancer. Semin Cancer Biol 2016; 40-41: 170-191

[28] Liao SG, Chen HD, Yue JM. Plant orthoesters. Chem Rev 2009; 109: $1092-1140$ 